\title{
A CONSTRUÇÃO DE UMA IDENTIDADE INSTITUCIONAL: POLÍTICAS EDUCACIONAIS E INFÂNCIA NOS PROJETOS PEDAGÓGICOS DO CEMEI DO CAIC PROF. ZEFERINO VAZ
}

\author{
THE BUILDING OF AN INSTITUTIONAL IDENTITY: EDUCATIONAL POLICIES AND \\ CHILDHOOD IN THE PEDAGOGICAL PROJECTS OF \\ THE CEMEI CAIC PROF. ZEFERINO VAZ
}

\section{LA CONSTRUCIÓN DE UNA IDENTIDAD INSTITUCIONAL: POLÍTICAS EDUCATIVAS Y LA INFANCIA EN LOS PROYECTOS PEDAGÓGICOS \\ DEL CEMEI DEL CAIC PROFESOR ZEFERINO VAZ}

RESUMO: O artigo analisa as múltiplas apropriações das normas institucionais, tomando como fonte os Projetos Pedagógicos elaborados no CEMEI do CAIC Prof. Zeferino Vaz, entre 1995 e 2008. As ideias de Chartier fundamentaram a investigação sobre as representações e apropriações tendo em vista a materialidade dos documentos. $\mathrm{O}$ artigo intenta apreender as maneiras pelas quais os profissionais deram sentido às suas práticas, registrando-as e justificando-as a partir do uso criativo das normas federais e municipais que permearam a implantação da instituição no município de Campinas/SP. A análise do uso dos termos que referenciaram a infância nos documentos permite ver a percepção teórica, normativa e ideológica que fundamentou a elaboração dos documentos produzidos no interior da escola. Os modos pelos quais o conjunto de Projetos Pedagógicos foi formulado a partir da escolha dos elementos constitutivos da política educacional e das concepções de infância remetem às práticas cotidianas e possibilitam observar as formas de construção da cultura e da identidade institucional.

PALAVRAS-CHAVE: Políticas educacionais. Educação infantil. Infância.

ABSTRACT : This article analyzes the multiples appropriations of institutional rules, taking as sources the Pedagogical Projects developed in CEMEI CAIC Prof. Zeferino Vaz in the period between 1995 and 2008. Chartier's ideias motivated the research on the representations and appropriations considering the document's materiality. The article tries to grasp the ways which professionals gave meaning to their practices, registering and justifying them from the creative use of federal and local rules that permeated the establishment of the institution in Campinas / SP. The analysis of the use of terms adopted to refer the childhood allows to see the theoretical, normative and ideological perception that justified the creation of the documents produced in the school. The ways in which the set of pedagogical projects was formulated, using the choice of constitutive elements of educational policy and conceptions of childhood, approach to common practices and possible ways to observe the construction of culture and institutional identity.

KEYWORDS: Educacional policy. Early childhood education. Childhood.

\footnotetext{
${ }^{1}$ Mestre e Doutoranda em Educação pela Universidade Estadual de Campinas - UNICAMP. Diretora Educacional da Prefeitura Municipal de Campinas - Campinas, SP - Brasil. E-mail: silvia.csi@ig.com.br Recebido em: 14/11/2014 - Aprovado em: 05/05/2015.
} 
RESUMEN: El artículo analiza los múltiples créditos de las normas institucionales, llevando cómo fuente los Proyectos Pedagógicos elaborados en el CEMEI del CAIC Profesor Zeferino Vaz entre los años de 1995 y 2008. Las ideas de Chartier fundamentaron la investigación sobre las representaciones y créditos en vista la materialidad de los documentos. El artículo tiene la intención de aprehender las maneras que los profesionales dieron sentido a las suyas practicas, las registrando y las justificando por el uso creativo de las normas federales y municipales que he permeado la implantación de la institución en el municipio de Campinas/SP. La análisis del uso de los termos que referencian la infancia en los documentos deja ver la percepción teórica, normativa y ideológica que fundamentó la elaboración de los documentos producidos en el interior de la escuela. Las maneras que el conjunto de Proyectos Pedagógicos fue formulado empezando por la elección de los elementos que constituyen la política educativa y de las concepciones de la infancia remeten a las prácticas cuotidianas y posibilitan observar las formas de construcción de la cultura y de la identidad institucional.

PALABRAS CLAVE: Políticas educacionales. Educación infantil. Infancia.

\section{INTRODUÇÃO}

Ao examinar os Projetos Pedagógicos produzidos pelo Centro Municipal de Educação Infantil (CEMEI) do Centro de Atenção Integral à Criança e ao Adolescente (CAIC) ${ }^{2}$ Prof. Zeferino Vaz no movimento histórico de constituição da proposta política para a educação da infância, percebe-se indícios da apropriação dos dispositivos legais deixados por seus profissionais. Por se tratar de uma instituição que integrou o complexo educacional CAIC, implantado no município de Campinas/ SP no início da década de 1990, teve como diretrizes de organização e funcionamento normas federais e municipais. Essa especificidade, apropriada pelos profissionais da escola, se constituiu em elemento para as práticas de educação da infância dessa instituição.

Pensando a infância como condição das crianças, que se relacionam entre si e com os adultos, com a cultura e a sociedade, conforme a compreensão de Kuhlmann Jr. e Fernandes (2004, p. 15) essa pesquisa buscou observar sob quais perspectivas os profissionais planejaram e registraram a vivência dessas crianças na instituição. Desse ponto de vista, a infância que emerge na documentação escolar, pode ser considerada como um discurso histórico delimitado pelas variáveis políticas e pedagógicas. Os Projetos Pedagógicos utilizados como fontes apresentam aspectos da representação da infância e abordam as práticas adotadas no cotidiano, a partir do entendimento dos profissionais sobre a infância e sobre as políticas para a sua educação.

Analisando os Projetos Pedagógicos produzidos no interior da escola em um período de $14 \operatorname{anos}^{3}$ (1995 a 2008), foi possível observar o modo como a infância foi percebida na

\footnotetext{
${ }^{2}$ Os CAICs foram complexos educacionais que fizeram parte das políticas sociais do governo federal da década de 1990. A pretensão era integrar educação, saúde, assistência e promoção social para crianças e adolescentes, atualizando as políticas de educação integral como aquelas idealizadas por Anísio Teixeira na década de 1950 e Darcy Ribeiro, na década de 1980. Devido às mudanças políticas, houve uma descontinuidade nessa proposta de educação integral e, como consequência, uma fragmentação dos núcleos do CAIC em unidades distintas, absorvidos pela administração municipal.

${ }^{3} \mathrm{O}$ recorte temporal se inicia com a inauguração da instituição de educação infantil e encerra com a legislação municipal que padronizou a produção dos projetos pedagógicos.
}

\begin{tabular}{l|l|l|l|l|l|l|}
\hline (C) ETD - Educ. temat. digit. & Campinas, SP & v.17 & n. 2 & p.414-426 & maio/ago. 2015 & ISSN 1676-2592
\end{tabular} 
instituição e permitiu compreender as concepções e os significados atribuídos a esse período da vida.

A descrição presente nesses documentos mostra as experiências vividas no interior da escola, constituídas a partir das interpretações individuais e coletivas sobre a infância e a criança. Da mesma forma que Bowe e Ball (1992) percebem o papel da apropriação da lei pelos profissionais, também no trabalho com a criança, foi possível perceber como a concepção de infância desses profissionais repercutiu nas decisões e diversas formas de atendimento. Assim, nas políticas para a educação da infância é possível utilizar as afirmações de Bowe e Ball (1992) sobre o ciclo de políticas ${ }^{4}$, considerando que os profissionais da escola exerceram um papel ativo no processo de interpretação e reinterpretação dessas políticas (Cf. PAULILO, 2010, p. 491).

A abordagem da análise também acompanha as palavras de Lajolo (2009, p. 229) quando considera a infância "um outro em relação àquele que a nomeia e a estuda. As palavras infante, infância (...) recobrem um campo semântico estreitamente ligado à ideia de ausência de fala". Examinando a noção de infância permeada pela ideia de silêncio, a análise buscou, nos registros das fontes, as representações e suas implicações nas práticas presentes no interior da escola. Conforme Lajolo (2009, p. 230),

Não se estranha, portanto, que esse silêncio que se infiltra na noção de infância continue marcando-a quando ela se transforma em matéria de estudo ou de legislação. Assim, por não falar, a infância não se fala e, não se falando, não ocupa a primeira pessoa nos discursos que dela se ocupam. E, por não ocupar esta primeira pessoa, isto é, por não dizer $e u$, por jamais assumir o lugar de sujeito do discurso e, consequentemente, por consistir sempre um ele/ ela nos discursos alheios, a infância é sempre definida de fora.

É nesse sentido que Kuhlmann Jr. e Fernandes (2004, p. 16) sugerem que no limite da significação, o termo infância é o período da palavra inarticulada, da construção/ apropriação de um sistema pessoal de comunicação, de signos e sinais destinados a fazer-se ouvir. Assim, examinando as fontes, que foram produzidas sob a perspectiva dos adultos, a pesquisa considerou, em consonância com Kuhlmann Jr. (1998, p. 31), que é preciso conhecer as representações de infância que permearam a produção dos registros nessa instituição de educação infantil no período delimitado.

\footnotetext{
${ }^{4}$ Bowe e Ball (1992) propuseram a análise das políticas educacionais por meio da abordagem de um ciclo contínuo, constituído por três contextos principais: o contexto de influência, o contexto da produção de texto e o contexto da prática. Esses contextos estão interrelacionados, não têm uma dimensão temporal ou sequencial e não são etapas lineares. Os autores entendem que o foco da análise de políticas deveria incidir sobre a formação do discurso da política e sobre a interpretação ativa que os profissionais que atuam no contexto da prática fazem para relacionar os textos da política à prática. Essa abordagem permite uma análise crítica e contextualizada de programas e políticas educacionais desde sua formulação até a sua implementação no contexto da prática.
} 
Por meio dos vestígios presentes nos enunciados dos Projetos Pedagógicos, foi possível apreender algo das representações que foram incorporadas no fazer da instituição. Conforme a compreensão da noção de representação de Chartier (1991), as diversas formas de perceber a criança na escola também foram parte de um processo dinâmico que marcou o trabalho com a infância.

\title{
2 OS TERMOS QUE DESIGNARAM A INFÂNCIA NOS PROJETOS PEDAGÓGICOS
}

Os Projetos Pedagógicos analisados apresentam, em seus registros, os termos infância, criança e aluno de forma indeterminada. Ainda assim, o uso desses termos mostra como os profissionais que participaram da produção desses documentos percebiam a infância no ambiente escolar.

Considerando que as "formas produzem sentido" (Cf. CHARTIER, 1991, p. 178), a organização textual e a materialidade dos documentos permitem pensar nas circunstâncias em que foram produzidos a partir do registro dos termos que referenciaram a infância.

Os Projetos Pedagógicos, a partir da forma específica de organização e em sua materialidade normativa, não apresentam em seus registros o termo infância nos quatro primeiros anos de funcionamento da instituição.

Dessa forma, a infância, pensada como condição necessária para o funcionamento da escola, foi condensada nos registros em propostas para a educação infantil, a partir do termo "criança". O texto do primeiro Projeto Pedagógico se aproximou da legislação, apresentando a intenção de complementação à família e foi baseado no pensamento de Wallon, quando se refere à descoberta do "eu", e de Vygotsky", quando usa como referência a expressão "zona de desenvolvimento proximal", como se pode observar no excerto:

\begin{abstract}
A educação infantil (...) deve considerar o grau de desenvolvimento da criança e a diversidade. Valoriza a integração (ela precisa do outro para descobrir o EU e precisa ser amada para gostar de si mesma e do mundo). As atividades são organizadas de acordo com o interesse e necessidade das crianças, atuando em sua zona de desenvolvimento proximal (CEMEI/ CAIC, 1995, p. 15).
\end{abstract}

\footnotetext{
${ }^{5}$ Os limites dessa pesquisa não permitiram tratar da psicologia sócio-histórica como paradigma de reflexão. Maior aprofundamento na questão pode ser encontrado nos estudos de LA TAILLE, Yves, OLIVEIRA, Marta K., DANTAS, Heloisa (1992); LURIA, Alexander R.; LEONTIEV, Alexis N., VYGOTSKY, Lev S. (1991); OLIVEIRA, Marta K. de (1993); RIVIERE, Angel (1988); SMOLKA, Ana L. B., GOES, M. C. R. (1993); VYGOTSKY, Lev S. (1987, 1989).
}

\begin{tabular}{ll|l|l|l|l|}
\hline (C) ETD - Educ. temat. digit. & Campinas, SP & v.17 & n. 2 & p.414-426 & maio/ago. 2015 \\
\hline
\end{tabular} 
Nesse sentido, observa-se que a representação dos profissionais sobre a educação da infância no CEMEI, além das políticas vigentes, considerou também a teoria do desenvolvimento infantil.

Os Projetos Pedagógicos dos três anos seguintes mantiveram as mesmas características, acrescidos da assertiva de que a educação infantil deveria "superar o caráter assistencial e promover o educacional, permitindo a criança crescer como sujeito independente e pensante" (CEMEI/ CAIC, 1996, p. 20). Nessa perspectiva, observa-se a concepção de superar o caráter assistencial como uma "nova" proposta para o desenvolvimento da criança.

Entretanto, de acordo com Kuhlmann Jr. (1998), certas concepções e propostas educacionais para a criança pequena não são fruto da história recente dessas instituições ${ }^{6}$.

Esse registro permite a compreensão de que para possibilitar o desenvolvimento da criança, seria necessário substituir o "assistencial" pelo "educacional". Nesse aspecto, percebe-se que, na representação da criança em crescimento, a autonomia seria alcançada se a instituição incorporasse o caráter educacional, considerado como superior ao assistencial. No entanto, as pesquisas de Kuhlmann Jr. (1998) indicam que as instituições de educação infantil sempre foram de cunho educacional. Segundo o autor, são inúmeras as referências ao caráter educacional das creches e pré-escolas assistencialistas. O fato de essas instituições carregarem em suas estruturas a destinação a uma parcela social específica, como foi o caso do CEMEI do CAIC, já representaria uma concepção educacional. Segundo o autor, se a educação assistencialista foi pensada no sentido de prever uma prática intencional, no interior de instituições constituídas para esse fim, pode se considerar que sempre tiveram natureza educacional.

Nos primeiros Projetos Pedagógicos, a narrativa se configurou a partir da concepção de educação infantil dos profissionais, sustentando no texto as operações de construção do sentido da infância. Nota-se que, entre 1995 e 1998, apesar da manutenção da proposta do

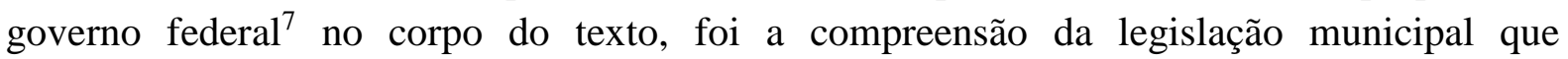
prevaleceu na forma de apresentação do trabalho educativo. O uso de siglas, como USE (Unidade Socioeducacionais), a estruturação e nomeação das turmas e os objetivos para a educação infantil se aproximaram das prescrições do Regimento Municipal, então vigente. Já

\footnotetext{
${ }^{6}$ As concepções educacionais vigentes nas creches vinculadas aos órgãos governamentais de serviço social, na década de 1970, se mostravam explicitamente preconceituosas, o que acabou por cristalizar a ideia de que, no passado, aquelas instituições teriam sido pensadas como lugar de guarda, de assistência, e não de educação. Nessa perspectiva, a história da educação infantil teria uma evolução linear, passando pela fase médica, depois assistencial para culminar, nos dias de hoje, na etapa educativa, entendida como superior, em contraposição aos outros aspectos (Cf. KUHLMANN JR., 1998, p. 182).

7 A proposta do governo federal incluía a unidade de educação infantil no complexo educacional. Os documentos orientadores do programa indicavam formas de organização e de integração entre os diversos núcleos que compunham o CAIC.
}

\begin{tabular}{l|l|l|l|l|l|l|} 
(C) ETD -Educ. temat. digit. & Campinas, SP & v.17 & n. 2 & p.414-426 & maio/ago. 2015 & ISSN 1676-2592
\end{tabular} 
a organização dos "conteúdos", subdivididos em linguagem, matemática e ciências, foi prevista nos Projetos Pedagógicos para as crianças a partir dos três anos. No entanto, a diretriz municipal não mencionou atividades diversificadas por faixa etária. A organização didática no documento oficial indicou o desenvolvimento da proposta curricular de forma geral para as crianças de 3 meses a 7 anos incompletos, "fundamentando toda a práxis educativa nos subsídios que são fornecidos pelos avanços das ciências da educação" (CAMPINAS, 1994, art. 70).

Dessa forma, a distinção das propostas por faixa etária, presente nos Projetos Pedagógicos desse período, remete à concepção de "educar" dos próprios profissionais da escola. Assim, as atividades educativas voltadas ao desenvolvimento cognitivo foram indicadas para as crianças maiores de 3 anos, enquanto que, para as crianças menores, o atendimento caracterizou-se por atividades de "cuidado", como preocupações com saúde, segurança, alimentação, carinho e respeito às etapas de seu desenvolvimento (Cf. CEMEI/ CAIC, 1996, p. 31). Nesse aspecto, as propostas de trabalho apresentaram um caráter mais "assistencial" para as crianças até 2 anos de idade, e mais "educativo" para as crianças acima de 3 anos.

O Regimento Municipal (CAMPINAS, 1994), apesar de conter seção específica sobre a assistência à criança, não fez distinção entre as faixas etárias, englobando, em seus artigos, o atendimento dos 3 meses aos 6 anos de idade. Dessa forma, os registros dos Projetos Pedagógicos mostram a apropriação da legislação municipal e sua construção a partir das condições culturais que acarretaram particularidades relacionadas às concepções de infância e às práticas de cuidado e de educação das crianças.

A mudança da estrutura textual, no ano de 1999, demonstrou outros modos de representação da infância e de educação infantil, que podem ser observados pela própria inclusão do termo infância nos discursos registrados:

O universo da educação infantil se amplia quando temos a concepção de que a criança além de estar incluída em uma faixa etária está no desenvolvimento sóciopolítico-cultural, de vivenciar a infância enquanto fase e nela se estabelecem direitos que se estendem a todos e além desses o direito ao lúdico, ao brincar, a ser considerada no presente e não a ser apenas preparada para o devir (CEMEI/ CAIC, 1999, p. 2).

O discurso considerou a criança incluída em uma faixa etária e pretendeu ampliar a concepção inserindo a questão da vivência de direitos. No entanto, quando apresentou a expressão "infância enquanto fase", reforçou a noção de que esse período representava uma fase biológica da vida, com subdivisões etárias. Assim, a articulação dos termos no registro indicia que a representação dos profissionais sobre a infância permaneceu atrelada às questões das divisões por idade. Nas palavras de Leite (2009, p. 21), "tendo em mente que a 
infância não é uma fase biológica da vida, mas uma construção cultural e histórica compreende-se que as abstrações numéricas ${ }^{8}$ não podem dar conta de sua variabilidade".

Nesse mesmo documento (Projeto Pedagógico de 1999), nos momentos em que o texto apresentou propostas relacionadas à aprendizagem, o termo utilizado, que caracterizou a infância, foi "aluno":

(...) Promover e facilitar o processo da aprendizagem dos alunos, bem como participar das mesmas causas da comunidade escolar (...). A escola deve planejar estratégias e possuir aparatos que permitam ao aluno o desenvolvimento de habilidades cognitivas, atitudinais, que conceda autonomia na continuidade do processo de aprendizagem (CEMEI do CAIC, 1999, p. 2).

Se por um lado, o texto apresentou a infância a ser considerada no presente, por outro, quando se reportou ao "aluno", indicou atividades que "preparem" para a continuidade do processo de aprendizagem. É sobre esse aspecto que Carvalho (1999, p. 75) afirma que a escola já não pode deixar de fora de seus muros a infância e a juventude e interessar-se pelo aluno no que ele tem de adulto.

Nesse sentido, percebe-se o uso do termo "aluno" ligado à ideia de aprendizagem e enfatizando o desenvolvimento da cognição, em um modelo próximo ao do ensino

fundamental. Nessa perspectiva, Kuhlmann Jr. e Fernandes (2004, p. 22) explicam que a "transformação da criança em aluno seria ao mesmo tempo a definição do aluno como criança, nesse processo em que o critério etário torna-se ordenador da composição e da seriação do ensino nas classes escolares".

A concepção de aluno pode remeter à ideia de criança como sujeito social à parte, com direitos a se tornarem objeto de ações específicas e adaptadas. Essa percepção pode ser considerada como o resultado de um modo de relação com a criança, que foi vista por Guy Vincent (2001) como a forma escolar de sociabilização:

Esta forma sui generis de relações com a criança, com as crianças, passa pela constituição da infância como categoria particular de sujeitos sociais separados, distintos de outros sujeitos sociais, suscetíveis de um tratamento particular: a educação. Esta categoria é, aliás, subdividida à medida que se processa a instauração de instâncias educativas específicas a cada idade... (p.43).

\footnotetext{
${ }^{8}$ Por abstrações numéricas, a autora refere-se à divisão da infância pela faixa etária presente na historiografia, como por exemplo: a maioridade aos 12 anos para meninas e 14 anos para meninos; 7 anos é a idade da razão para a Igreja Católica, que normatizou toda a vida das famílias até o final do século XIX; dos 8 aos 12 anos os meninos são considerados adultos-aprendizes e vestem-se como tais.
} 
Dessa forma, os registros nos Projetos Pedagógicos que incluíram os termos criança, infância e aluno num mesmo texto, permitem a interpretação de que, apesar da separação espacial da instituição de ensino fundamental, a criança enquanto aluno foi uma forma de perceber a infância na situação especificamente escolar. Nas palavras de Narodowski (2001, p. 23), a criança e o aluno correspondem existencialmente a um mesmo ser, mas epistemologicamente constituem objetos diferentes. Para o autor, o aluno é um campo de intervenção não alheio à infância, porém mais complexo. A criança aparece em um primeiro momento como razão necessária para a construção do objeto aluno. Nesse sentido, a complexidade das representações de criança, infância e aluno, podem ter incluído sentidos que nem sempre foram apreendidos da mesma forma pelos profissionais.

A criança como protagonista na educação infantil esteve presente nos discursos registrados nos Projetos Pedagógicos no período de 2000 a 2003:

Centrar-se na criança como ser que é, em seu tempo de infância, com capacidades, potencialidades, limites e dificuldades próprias do ser humano, mas que precisam ser consideradas e trabalhadas na escola (CEMEI/ CAIC, 2000, p. 6).

Nesse excerto, observa-se a concepção de criança ligada ao tempo de infância. Veiga (2004, p. 39), inspirando-se nas ideias de Norbert Elias, compreende o tempo não como conceito, mas como um símbolo cultural. Nessa perspectiva, o tempo é percebido como uma forma de organizar o curso da vida e relacionar diferentes processos e acontecimentos. $\mathrm{O}$ tempo de infância tratado no Projeto Pedagógico foi delimitado pela vertente da política de atendimento: crianças de 0 a 6 anos. Assim, considerando o tempo não como meramente instrumental, mas como uma dimensão da experiência humana (Cf. VEIGA, 2004), o registro, por um lado, apresenta as características da criança, admitidas como próprias desse tempo. Por outro, o registro completa que essas especificidades precisariam ser trabalhadas na escola. Nesse sentido, a apropriação que se operou no discurso permite a compreensão de que os procedimentos escolares seriam centrais, legitimando as propostas para a educação da infância.

A abordagem de criança em seu "tempo de infância", admitindo capacidades e limites a ser trabalhados na escola, possibilita a compreensão da infância como algo a ser forjado, interessando explorar o próprio processo, que termina por delinear a força daquilo que o termo infância pretende descrever (Cf. GONDRA, 2010). É nesse sentido que Gondra define a infância como um "período da existência humana constituída por um sistema normativo, que lhe atribui características, formas, competências e funções, precisas ou fluidas, ancoradas em sistema de ordenações, que cada grupo social relaciona ao seu sistema valorativo" (GONDRA, 2010, p. 196). 
Kuhlmann Jr., Fernandes e Gondra concordam que a criança pode ser considerada como uma realidade psicobiológica referenciada ao indivíduo, que, em situação escolar, também é passível de ser "mensurável e quantificável”".

Dessa forma, a ideia de infância construída com base em um sistema normativo foi sendo atualizada pelas múltiplas formas de apropriação e legitimadas e reproduzidas pelo processo de escolarização, traçado a partir da forma escolar de socialização.

Outro aspecto a ser considerado na análise dos registros do trabalho educativo foi a questão dos direitos da infância, incluídos no conjunto dos Projetos Pedagógicos no período de 2004 a 2007. Observa-se um deslocamento na apresentação da proposta educacional centrada na infância a ser trabalhada na escola, sob a perspectiva das capacidades e dificuldades desse período da vida, para o que os profissionais entendiam por infância, a partir de suas próprias experiências e lembranças:

A proposta educacional está centrada no que entendemos por infância. Lembramos de nossa infância, de nossas brincadeiras, das vivências, das experiências culturais e das múltiplas relações que estavam presentes nos diferentes espaços e tempos de nossos cotidianos. A partir daí, pensamos na intencionalidade do nosso trabalho pedagógico, no qual a criança deva ter a garantia na sua infância de inúmeros direitos: o direito de brincar, de ter contato com a natureza, de conhecer a cultura historicamente construída, ter espaço e de usufruir cuidados básicos (CEMEI/ CAIC, 2004, p. 13).

A forma como esse discurso foi articulado expressou uma ideia otimista das lembranças da infância. A memória, como uma propriedade de conservar certas informações, de acordo com Le Goff (1992, p. 423), "remete-nos em primeiro lugar a um conjunto de funções psíquicas, graças às quais o homem pode atualizar impressões ou informações passadas ou que ele representa como passadas". Nesse aspecto, a lembrança das brincadeiras, vivências, experiências e relações do cotidiano indicam que, na atualização das informações sobre a infância na qualidade de experiência pessoal para elaboração do enunciado, os fenômenos que foram reconstituídos trouxeram uma representação positiva do passado.

Assim, nesse registro, percebem-se duas vertentes de compreensão do trabalho com a educação infantil. Por um lado, observa-se uma representação de infância evocada em uma perspectiva otimista e saudosa. Marisa Lajolo (2009, p. 233) explica que essa imagem idílica pode ter relação com a poesia romântica, que construiu a representação dos primeiros anos de vida como um período sem conflitos. Como exemplo, a autora cita os versos da poesia Meus oito anos, de Casimiro de Abreu: "Oh! que saudades que tenho da aurora da minha vida/ Da

\footnotetext{
${ }^{9}$ De acordo com Gondra (2010), a institucionalização maciça da criança pequena obriga a pensar esse fenômeno de massa como parte de uma tecnologia de governo. Nesse sentido, as crianças também são passíveis de serem descritas em termos de população - esse novo corpo múltiplo, mas quantificável, localizável, mensurável. Tratase de saber quantos são? Onde estão? Que idades possuem? Qual seu sexo? Que cor possuem? De onde provêm? Nessa chave, a ideia de infância passa a estar associada à de população infantil - uma ideia muito recente, que, no Brasil, tem apenas algumas décadas.
}

\begin{tabular}{l|l|l|l|l|l|l|} 
(C) ETD - Educ. temat. digit. & Campinas, SP & v.17 & n. 2 & p.414-426 & maio/ago. 2015 & ISSN 1676-2592
\end{tabular} 
minha infância querida/ Que os anos não trazem mais!”. Ainda segundo ela, essa representação edênica da infância parece ter calado fundo no imaginário brasileiro a ponto de se transformar em clichê. Por outro lado, observa-se a apropriação das legislações que previam a garantia dos direitos da criança, aproximando o discurso das normas que direcionaram a produção dos documentos. Nesse sentido, a proposta novamente fica próxima a um modelo ideal de educação infantil: os direitos garantidos para uma infância sem conflitos. Dessa forma, o uso da memória como recurso para elaboração da proposta educacional pode ser considerado como um elemento na construção da identidade da instituição. A partir dessa proposta, as imagens que foram evocadas transmitiram a recordação dos acontecimentos que mereceram ser conservadas (Cf. LE GOFF, 1992), mesmo que essas lembranças fossem apresentadas a partir de uma representação idealizada do passado dos profissionais.

Ainda no sentido da elaboração de discursos construídos a partir da apropriação do processo histórico da educação infantil, os registros apresentam a representação da instituição como lugar em que a criança poderia "usufruir de cuidados básicos". Assim, o discurso sobre a "intencionalidade do trabalho pedagógico" envolveu as lembranças positivas dos profissionais sobre a infância, além de considerar os direitos e os cuidados da criança na instituição.

Os Projetos Pedagógicos desse período também enfocaram a questão das interações e relações, sob a luz da teoria do desenvolvimento infantil, ao modo de Vygotsky, Wallon e Piaget. Esses projetos ainda propuseram práticas educativas que contemplaram o cuidar e o educar, respeitando as diferenças das crianças e a garantia dos direitos sob a perspectiva da apropriação das políticas para a educação da infância.

Os registros do Projeto Pedagógico de 2008 mantiveram as mesmas características discursivas dos anos anteriores nos aspectos teóricos e legislativos. A essas propostas, acrescentou-se que "a educação infantil é uma fase de reconhecimento de um tempo cheio de novidades, prazeres e construções" (Cf. CEMEI/ CAIC, 2008 p. 91). Nesse registro, observase que "educação infantill" refere-se mais à infância do que à instituição. Na perspectiva de Kuhlmann Jr. (1998, p. 31), as crianças apropriam-se de valores e comportamentos próprios de seu tempo e lugar. Nesse processo psicológico, social, cultural e histórico de interação, percebe-se que as relações estabelecidas no interior da escola permitiram a enunciação de um conjunto de características que se tornaram comuns tanto à instituição de educação infantil quanto à infância.

Visando a compreender como a infância e a educação infantil foram percebidas nos documentos produzidos no interior da escola a partir da representação dos profissionais, considera-se pertinente a advertência de Chartier (1990, p. 63) de que "nenhum texto mantém uma relação transparente com a realidade que apreende". 


\section{CONSIDERAÇÕES FINAIS}

Os Projetos Pedagógicos foram configurados para atender a uma organização burocrática. Organização operacionalizada em conformidade com os meios práticos utilizados pela escola para concretizar sua ação, a partir dos meios legais definidos pela política de atendimento. Tendo em vista a análise da construção dessa política de atendimento pela pedagogia burocrática, conforme a compreensão de Formosinho e Araújo (2007, p. 300), percebe-se que há uma conformidade dos meios práticos com os meios legais, de modo que é possível "avalizar ou mesmo fomentar a existência de práticas claramente desviantes em relação aos fins definidos". Nessas circunstâncias, os documentos contemplaram as particularidades da instituição no que diz respeito às políticas de atendimento e referenciais teóricos indicados para sua produção, mas também mostraram "práticas desviantes" fundamentadas nas representações dos profissionais.

Entre o que se propôs como políticas públicas federais e municipais nessa instituição e o que se configurou nos Projetos Pedagógicos observam-se os modos de percepção e representação do que se entendeu ser o trabalho com a educação da infância. Esses modos de ver e pensar, registrados nos documentos, circunscreveram as práticas da instituição e indicaram as formas pelas quais as concepções de infância dos profissionais foram construídas, registradas e justificadas.

Nessa perspectiva, a pesquisa permitiu uma forma de compreensão das políticas para a infância no CEMEI do CAIC Prof. Zeferino Vaz, com especial atenção às múltiplas apropriações que os sujeitos fizeram das referências teóricas e normativas. Além disso, possibilitou ver as concepções sobre a infância no uso da terminologia que a referenciou nos documentos. Essas formas de uso criativo das políticas para a educação da infância e a representação da criança em ambiente escolar constituíram uma cultura própria e foram fundamentais na construção da identidade institucional.

\section{REFERÊNCIAS}

BOWE, Richard; BALL, Stephen J.; GOLD, Annie. Reforming education and changing schools: case studies in policy sociology. London: Routledge, 1992.

CAMPINAS. Divisão Regional de Ensino. Aprova o Regimento Escolar. Portaria, n. 58/94, de 29 de julho de 1994. Diário Oficial do Município. Campinas, SP, DREC, 1994.

CARVALHO, Marília Pinto. No coração da sala de aula - gênero e trabalho docente nas séries iniciais. São Paulo: Xamã, Fapesp, 1999

CEMEI/ CAIC Prof. Zeferino Vaz. Plano Escolar. Campinas, SP, 1995. 96 fls.

CEMEI/ CAIC Prof. Zeferino Vaz. Projeto Pedagógico. Campinas, SP, 1996. 79 fls.

CEMEI/ CAIC Prof. Zeferino Vaz. Projeto Pedagógico. Campinas, SP, 1997. 57 fls.

\begin{tabular}{l|l|l|l|l|l|l|} 
(C) ETD - Educ. temat. digit. & Campinas, SP & v.17 & n. 2 & p.414-426 & maio/ago. 2015 & ISSN 1676-2592
\end{tabular} 
CEMEI/ CAIC Prof. Zeferino Vaz. Plano Escolar. Campinas, SP, 1998. 61 fls.

CEMEI/ CAIC Prof. Zeferino Vaz. Projeto Pedagógico. Campinas, SP, 1999. 50 fls.

CEMEI/ CAIC Prof. Zeferino Vaz. Plano Escolar. Campinas, SP, 2000. 59 fls.

CEMEI/ CAIC Prof. Zeferino Vaz. Plano Escolar. Campinas, SP, 2001. 40 fls.

CEMEI/ CAIC Prof. Zeferino Vaz. Plano Escolar. Campinas, SP, 2002. 31 fls.

CEMEI/ CAIC Prof. Zeferino Vaz. Plano Escolar. Campinas, SP, 2003. 34 fls.

CEMEI/ CAIC Prof. Zeferino Vaz. Plano Escolar. Campinas, SP, 2004. 33 fls.

CEMEI/ CAIC Prof. Zeferino Vaz. Projeto Pedagógico. Campinas, SP, 2005. 61 fls.

CEMEI/ CAIC Prof. Zeferino Vaz. Projeto Pedagógico. Campinas, SP, 2006. 67 fls.

CEMEI/ CAIC Prof. Zeferino Vaz. Projeto Pedagógico. Campinas, SP, 2007. 57 fls.

CEMEI/ CAIC Prof. Zeferino Vaz. Plano Escolar/Projeto Pedagógico. Campinas, SP, 2008. 93 fls.

CHARTIER, Roger. História Cultural. Entre práticas e representações. Lisboa/Rio de Janeiro: Difel/Bertrand Brasil, 1990.

CHARTIER, Roger. O mundo como representação. Estudos avançados, v. 11, nº 5, p. 173$191,1991$.

FORMOSINHO, João; ARAÚJO, Joaquim Machado de. Anônimos do século XX: a construção da pedagogia burocrática. In. OLIVEIRA-FORMOSINHO, Júlia (Org.); KISHIMOTO, Tizuko Morchida (Org.); PINAZZA, Mônica Appezzato (Org.). Pedagogia(s) da infância: dialogando com o passado, construindo o futuro. Porto Alegre: Artmed, 2007.

GONDRA, José Gonçalves. A emergência da infância. Educ. rev. [online]. vol.26, n.1, pp. 195-214. ISSN 0102-4698, 2010.

KUHLMANN JÚNIOR, Moysés; FERNANDES, Rogério. Sobre a história da infância. In. FARIA FILHO, Luciano Mendes (Org.). A infância e sua educação - materiais, práticas e representações. Belo Horizonte: Autêntica, 2004.

KUHLMANN JÚNIOR, Moysés. Infância e educação infantil: uma abordagem histórica. Porto Alegre: Mediação, 1998.

LAJOLO, Marisa. A infância de papel e tinta. In. FREITAS, Marcos Cezar de. (Org.)

História Social da Infância no Brasil. 7.ed. - São Paulo: Cortez, 2009.

LA TAILlE, Yves; OLIVEIRA, Marta Kohl; DANTAS, Heloisa. Piaget, Vygotsky, Wallon: teorias psicogenéticas em educação. São Paulo: Summus, 1992. 
LE GOFF, Jacques. História e memória. Tradução Bernardo Leitão ... [et al]. 2. ed. Campinas, SP: Editora da UNICAMP, 1992.

LEITE, Miriam L. Moreira. A infância do século XIX segundo memórias e livros de viagem. In. FREITAS, Marcos Cezar de. (Org.) História social da infância no Brasil. 7.ed. - São Paulo: Cortez, 2009.

LURIA, Alexander R.; LEONTIEV, Alexis N.; VYGOTSKY, Lev S. Psicologia e pedagogia. São Paulo: Moraes, 1991.

NARODOWSKI, Mariano. Infância e poder: a conformação da Pedagogia Moderna. Bragança Paulista: Universidade São Francisco, 2001.

OLIVEIRA, Marta Kohl de. Vygotsky: aprendizado e desenvolvimento, um processo histórico. São Paulo: Scipione, 1993.

PAULILO, André Luiz. A pesquisa em políticas públicas de educação numa perspectiva histórica. Revista Brasileira de Estudos Pedagógicos. Brasília, v 91, n.229 p. 481-510, set/dez 2010.

RIVIERE, Angel. La psicologia de Vygotsky. Madri: Visor, 1988.

SMOLKA, Ana Luiza Bustamante (Org.); GOES, Maria Cecília R. (Org.). A linguagem e o outro no espaço escolar: Vygotsky e a construção do conhecimento. Campinas, SP:

Papirus, 1993.

VEIGA, Cyntia Greive. Infância e modernidade: ações, saberes e sujeitos. In. FARIA FILHO, Luciano Mendes (Org.). A infância e sua educação: materiais, práticas e representações. Belo Horizonte: Autêntica, 2004.

VINCENT, Guy; LAHIRE, Bernard; THIN, Daniel. Sobre a história e a teoria da forma escolar. Educação em Revista, Belo Horizonte, p. 7-48, jun. 2001.

VYGOTSKY, Lev S. A formação social da mente. São Paulo: Martins Fontes, 1989.

VYGOTSKY, Lev S. Pensamento e linguagem. São Paulo: Martins Fontes, 1987.

\section{Como citar este documento:}

VALLEZI, Silvia. A construção de uma identidade institucional: políticas educacionais e infância nos projetos pedagógicos do CEMEI do CAIC Prof. Zeferino Vaz. ETD - Educação Temática Digital, Campinas, SP, v. 17, n. 2, p. 414-426, ago. 2015. ISSN 1676-2592. Disponível em:

<http://periodicos.sbu.unicamp.br/ojs/index.php/etd/article/view/8634864>. Acesso em: 28 ago. 2015. 